\title{
Customized Versus Standardized Exams For Learning Outcomes Assessment In An Undergraduate Business Program
}

Amy L. Phelps, Duquesne University, USA

William E. Spangler, Duquesne University, USA

\begin{abstract}
A standardized exam for program-level assessment can take the form of 1) a customized exam developed in-house by faculty and linked explicitly to program-level learning goals; or 2) a standardized exam developed externally by assessment experts and linked to a set of somewhat broader and more generalizable learning goals. This article discusses the design, development and implementation of a customized exam and subsequent transition to a commercial exam (i.e., the ETS Major Field Test), within an undergraduate business program. We discuss the lessons learned from our experience with the customized exam, our analysis of both the assessment process and the results gathered (primarily curriculum-related), and the rationale underlying the eventual migration to the commercial exam. Of particular emphasis is the situation-dependent and potentially complementary roles of the customized and commercial exams. In this regard we provide a comparison of the two approaches through a framework based on a set of administrative and assessment considerations. They include: relevance to learning goals, exam design and development process, delivery of the exam, impact on learning, impact on courses and curriculum, and impact on student monitoring and management. We note that although the customized exam no longer exists as a standalone assessment instrument, it continues to play a role in assessment by complementing other methods. This outcome, as well as the process leading to it, are potentially applicable to other institutions pursuing an evolutionary approach to learning outcomes assessment.
\end{abstract}

Keywords: Program-Level Outcomes Assessment; Standardized Exam; Major Field Test

\section{INTRODUCTION}

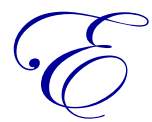

xternal stakeholders - particularly the federal and state governments, accrediting agencies, and potential students and their parents - are holding institutions of higher education increasingly accountable for the quality of education they are providing their students (Altbach, Gumport, \& Berdahl, 2011). In the specific domain of business higher education, schools accredited by the Association to Advance Collegiate Schools of Business (AACSB) are subject to specific assessment standards, guidelines and reporting practices prescribed by the association (AACSB, 2012). In order to ensure and demonstrate student learning, business schools have responded by developing and implementing formal outcomes assessment plans (Bisoux, 2008). But while clear assessment planning and sound direct measurement is a critical prerequisite for program review, assurance of learning, and maintenance of accreditation, many schools have struggled with finding and implementing a sustainable process for outcomes assessment (Kuh \& Ewell).

Common approaches to outcomes assessment range from direct course-level assessment to direct and indirect program-level assessment (Marshall, 2007; Walvoord, 2004). Course-level assessment focuses on the operational elements of classroom learning and the specific learning goals of the course. It includes the use of preand post-testing, common exams, and grading rubrics, among others (Walvoord, 2004). By contrast, program-level assessment is a strategic, top-down approach consolidating assessment in individual courses, while also including 
strategies that assess learning across the curriculum and over time (Marshall, 2007; Walvoord, 2004). Programlevel assessment naturally attends to program-level goals, which in our organization address general business skills expected of all business students.

In this paper we provide a description and analysis of 'lessons learned' from our use of multi-disciplinary proficiency exams to assess undergraduate student learning prior to graduation. Specifically we discuss the creation and delivery of two objective exams intended to assess learning in various business disciplines. The first exam, which essentially was experimental, was developed in-house and designed for implementation following the sophomore year. As such, it measured learning in each of the freshman and sophomore business core classes. After deployment for three consecutive years, the customized exam, which we had labeled the 'Core Competency and Proficiency Exam' (CCPE), was discontinued and replaced by the senior-level ETS Major Field Test, a standardized exam used by hundreds of business schools across the country.

Our experience in deploying these exams over a 6-7 year period led to a number of observations and conclusions that guided both refinement of our assessment strategy as well as changes to our curriculum and delivery methods. As we discuss in more detail later, both of the exams provided valuable information regarding student learning outcomes. However, the process of creative experimentation that led to on-going changes in the content and delivery of the exams, particularly changes to the CCPE, provided significant insights into the nature and challenges of customized exam construction and exam delivery, as well as into the characteristics of our sophomore class. This in turn reveals insights that were gleaned from an analysis of two essentially similar but still very different exams. Both exams are similar in that they are objective tests seeking to assess learning in specific business disciplines at a particular point in time. But they are different in that they were developed by different groups of academics, targeted to different audiences, and delivered at different points in time. Viewed in this context, a comparison of the two exams over time provides highly useful and actionable feedback regarding the process of program-level outcomes assessment through testing.

The remainder of the paper is as follows. A short literature review provides background regarding assessment of learning and, more specifically, the various uses of standardized, customized and commercial exams for outcomes assessment. Next we describe in some detail the conception, development and implementation of the CCPE, including the trial-and-error aspects of it and the statistical analysis of the results. We also describe how and why we eventually chose to discontinue the use of the CCPE and search for another method. Then we discuss, in somewhat less detail, the move to the ETS Major Field Test and the delivery strategy employed. We conclude by comparing and contrasting the two exams with regard to their relative advantages and disadvantages.

\section{EXAM-BASED APPROACHES TO ASSESSMENT OF LEARNING}

Assessment of student learning is widely considered to require a variety of direct and indirect measurement strategies (Mirchandani, Lynch, \& Hamilton, 2001). A multi-modal approach often is required because each method in isolation is insufficient to fully assess student learning, (Michlitsch \& Sidle, 2002). As such, institutions tend to employ a variety of methods (Pringle \& Michel, 2007), and they naturally tend to focus on the methods that are considered most effective (Michlitsch \& Sidle, 2002), such as portfolio analysis, case study evaluations, analysis of group assignments, and standardized exams (Peterson \& Einarson, 2001; Ruhland \& Brewer, 2001; Walstad, 2001; Walvoord, 2004).

Within the context of a multi-modal approach, standardized exams are a common form of both programand course-level assessment (Black \& Duhon, 2010). They offer the advantages of convenience, the ability to assess an extensive range of topics, objective grading resulting in consistent evaluation across students and evaluators and finally offer the advantage of evaluating large numbers on students in a reasonably short time-frame (Callahan, Strandholm, \& Dziekana, 2009). Weaknesses of standardized exams include the risk of 'teaching to the test' (Firestone, Monfils, \& Schorr, 2004), as well as a strong bias toward subject-matter content at the expense of other types of learning such as communication (Barnett, Dascher, \& Nicholson, 2004).

Standardized exams can take one of two forms: they can either be developed in-house by the faculty of the assessing institution (i.e., customized), or they can be purchased from a commercial testing service (Callahan et al., 
2009). Each has its advantages and disadvantages. For customized exams, the major advantage is the ability to target the exam to the individual mission program goals of the department or school, thus ensuring that the unique characteristics of the program are addressed and highlighted (Angelo \& Cross, 1993; Apostolou, 1999; Black \& Duhon, 2010; Callahan et al., 2009). For these reasons, any results are more likely to be accepted by the faculty (Callahan et al., 2009). For commercial exams, the major advantages are a rigorous development process conducted by testing experts, as well as a common set of questions and topics that can be used to benchmark the program against similar programs at other schools (Black \& Duhon, 2010; Callahan et al., 2009; Mirchandani et al., 2001). The respective disadvantages in turn tend to mirror each other. A customized exam is somewhat idiosyncratic and therefore difficult to benchmark against other schools, and is developed by faculty who are not necessarily experts in test design. A commercial exam in turn is not directly linked to the mission or program goals (Allen, 2004; Apostolou, 1999), and as such the faculty might consider the results irrelevant (Callahan et al., 2009).

Because of their advantages, and despite their drawbacks, commercial exams are used extensively for outcomes assessment. A widely used commercial exam is the Educational Testing Service's Major Field Test (MFT), which from September 2010 to June 2011 was administered by over 400 colleges and universities (ETS, 2012). As such, numerous studies have explored implementation of the MFT from a variety of perspectives, including:

- $\quad$ the determinants of students performance on the MFT (see, for example, (Bagamery, Lasik, \& Nixon, 2005; Barboza \& Pesek, 2012; Bush, Duncan, Sexton, \& West, 2008; Bycio \& Allen, 2007; Contreras, Badua, Chen, \& Adrian, 2011; Mirchandani et al., 2001; Terry, Mills, Rosa, \& Sollosy, 2009; Terry, Mills, \& Sollosy, 2008; Thornton \& Arbogast, 2012)

- $\quad$ the MFT as an indicator of student engagement (Ward, Yates, \& Soong, 2009, 2010, 2012)

- $\quad$ the MFT as a tool for improving learning (Black \& Duhon, 2010; Wilson, 2008)

- $\quad$ a case or field study discussing specific implementations of the MFT (Bush et al., 2008; Contreras et al., 2011)

By contrast, relatively less attention and research has been devoted to the effectiveness of customized exams. A notable exception is (Callahan et al., 2009), who describe the process used to develop, validate and deploy a customized exam in-house, as well as the challenges inherent in such a process (noted above). Despite the challenges, the authors note that their effort thus far has been successful, and that they intend to continue to refine and enhance their customized instrument. Our work is complementary to the work of Callahan et al in that while we also began with the development and implementation of a customized exam, we ultimately chose to move on to a commercial approach. In the following sections, we discuss the evolution of our customized approach, the lessons learned from its implementation, and the factors that led us to replace it with the ETS Major Field Test.

\section{DESIGN, DEVELOPMENT AND DELIVERY OF THE CUSTOMIZED EXAM}

The evolution of the customized exam from inception to the first implementation took place over a sixmonth period. The exam was administered six semesters over a three-year period during which the logistics of administration were evaluated and changed and student assessment was reviewed. The three-year process included the following phases:

1. Design and development of a customized assessment instrument (CCPE)

2. Implementation/delivery of the customized instrument, through multiple iterations

3. Review and analysis of the assessment data

4. Review and evaluation of the customized approach, including lessons learned

\section{Phase 1: Initial Design of the Customized Exam (CCPE)}

The customized exam was designed to assess the nine freshman and sophomore core courses in the business school. These courses included (with abbreviations): Introduction to Information Systems (IS 1), Business Information Systems (IS 2), Business Law (BLaw), Financial Accounting (Fin Acct), Managerial Accounting (Mgrl Acct), Micro-Economics (Micro Econ), Macro-Economics (Macro Econ), and Business Statistics I and II (BStats I 
$\& I I)$. The departments involved were asked to submit ten multiple choice questions for each of the ten learning objectives of each core course. This would create a pool of 100 questions for each of the nine courses to be assessed. The summer before the first administration of the exam was spent collecting the questions and inputting them in our Blackboard Course Management site. From this pool of test questions we created a 90 question assessment that represented the ten learning objectives from each of the nine core courses.

\section{Phase 2: Administration of the Assessment}

We initially chose to administer the exam in a junior level required course, believing that this would naturally enforce $100 \%$ participation. The exam was administered using an electronic bubble scoring sheet allowing for quick grading and printouts of detailed item analyses. From this analysis, each department would be able to receive the overall assessment grade, grades from each course sub-test and percent of students scoring on each of the ten questions for each of the core courses. The exam was given in the same junior level course during the fall and spring semesters.

\section{Phase 3: Review and Analysis of the Data}

At the end of each academic year, the scores for the Fall and Spring administrations were combined and summary statistics were given to each department responsible for teaching one or more of the nine courses assessed. The summary statistics included the distribution of the overall assessment grades, the grades for each of the core course subtests of ten questions each, the item analysis summarizing the percent of students correctly answering each question within the department's subtests, and the corresponding point bi-serial analysis for each question. Student performance on the overall exam and each course subtest was externally validated with the student's grade point average and grades received in each core course, respectively, using Pearson's correlation coefficients. After administering the exam for at least two years, multiple linear regression was performed to identify the strongest predictors of how well a student would perform on this internally generated assessment. Independent predictors included the student's GPA and the year the exam was administered.

As part of the review of the results, we asked each department to reconsider each question selected for the assessment, and to rank the question for level of difficulty (easy, medium or hard) and for its category in Bloom's Taxonomy (Knowledge, Concept, Application, Analysis and Synthesis). Each department was given a detailed summary report which included:

\section{A. Overall Exam Performance}

1. The mean score for all 90 questions

2. The correlation coefficient measuring association between student score and student GPA

3. The results of the overall multiple linear regression analysis (following the second and third year)

B. Individual Department Sub-tests Performances

1. The mean subtest score for the ten questions assessing their particular core course(s)

2. The correlation coefficient measuring association between student score and student grade for each core course assessed from their department

3. The distribution of Bloom's taxonomy for each of the ten subtest questions for the core course(s)

4. The distribution of the perceived level of difficulty for each of the ten subtest questions for the core course(s)

5. The point bi-serial estimate for each of the ten subtest questions for the core course(s)

Results: Program Review

The overall program review was summarized using the correlation between the exam scores and student grade point average. Despite a low mean score of around $50 \%$ on the exam, the correlation between the exam scores and student grade point average was 0.514 , indicating a strong external validation of the exam. While students 
might be retaining only about $50 \%$ of the course material, the exam correctly identified higher grade point averages with higher CCPE performance. After three years of administering the exam, regression analysis confirmed that overall mean scores significantly improved annually and students with higher QPA's scored significantly higher. The multiple linear regression model predicted an increase of approximately $2 \%$ with each subsequent year and about a $12.3 \%$ increase for every 1 point increase in QPA.

The review also exposed a problem in student management, subsequently resolved, which became apparent prior to the administration of the first assessment. In the first year we discovered that many of our students were not 'on track' within the proposed curriculum. Of the 221 eligible juniors, only 121 (or 54.6\%) had successfully completed all nine of the freshman/sophomore core courses on time. Although this was problematic with regard to the administration and analysis of the exam, it also provided the unexpected benefit of highlighting a significant problem in student management. Thus, from an assessment perspective, we formulated a program-level response plan that addressed student class scheduling and enforced the suggested curriculum sequence. We also turned to the departmental summaries (detailed in the next section) to troubleshoot curricular changes in an effort to improve overall retention of core business outcomes.

\section{Results: Departmental Review}

The second set of results pertains specifically to student performance on the individual department subtests. Table 1 summarizes the mean scores (percentage of the ten questions correct) for each of the nine subtests, the mean course grade (on a 4-point grading scale) received by students for each of the nine core courses, and the correlation of student performance on the CCPE exam with grades earned for each of the nine courses. The table also includes the departmental question reviews regarding: 1) which percentage of questions within each subtest were internally rated as 'written clearly', 2) the percentage perceived as medium or highly difficult, and 3) the percentage labeled cognitively higher on Bloom's Taxonomy (i.e., Application, Analysis or Synthesis). Results are reported for each of the three years except the specialized item analysis which was only reported for the first year to be used to inform immediate curricular changes.

Table 1: Mean Score, GPA, Score-Grade Correlation, and Question Review by Course

\begin{tabular}{|c|c|c|c|c|c|c|c|c|c|}
\hline & IS 1 & IS 2 & $\begin{array}{l}\text { Micro } \\
\text { Econ }\end{array}$ & $\begin{array}{l}\text { Mgrl } \\
\text { Econ }\end{array}$ & $\begin{array}{c}\text { Mgmt } \\
\text { Acct }\end{array}$ & $\begin{array}{c}\text { Fin } \\
\text { Acct }\end{array}$ & BStats I & BStats 2 & BLaw \\
\hline $\begin{array}{l}\text { Mean Score \% } \\
\text { Year1 } \\
\text { Year2 } \\
\text { Year3 }\end{array}$ & $\begin{array}{l}69.8 \\
47.0 \\
75.7\end{array}$ & $\begin{array}{l}54.0 \\
44.7 \\
75.7\end{array}$ & $\begin{array}{l}48.6 \\
51.8 \\
55.9\end{array}$ & $\begin{array}{l}40.7 \\
50.3 \\
55.4\end{array}$ & $\begin{array}{l}61.7 \\
40.8 \\
63.1\end{array}$ & $\begin{array}{l}51.0 \\
44.7 \\
44.7\end{array}$ & $\begin{array}{l}48.5 \\
47.2 \\
57.3\end{array}$ & $\begin{array}{l}41.5 \\
42.9 \\
43.2\end{array}$ & 46.6 \\
\hline $\begin{array}{l}\text { Mean Course Grade } \\
\text { Year1 } \\
\text { Year2 } \\
\text { Year3 }\end{array}$ & $\begin{array}{l}3.00 \\
3.24 \\
2.76\end{array}$ & $\begin{array}{l}3.22 \\
3.22 \\
2.76\end{array}$ & $\begin{array}{l}2.70 \\
2.94 \\
2.71\end{array}$ & $\begin{array}{l}2.75 \\
3.07 \\
2.88\end{array}$ & $\begin{array}{l}2.98 \\
2.95 \\
2.95\end{array}$ & $\begin{array}{l}2.91 \\
2.79 \\
2.80\end{array}$ & $\begin{array}{l}3.11 \\
3.10 \\
2.54\end{array}$ & $\begin{array}{l}3.02 \\
2.98 \\
2.84\end{array}$ & 2.77 \\
\hline $\begin{array}{l}\text { Correlation } \\
\text { Year1 } \\
\text { Year2 } \\
\text { Year3 }\end{array}$ & $\begin{array}{l}0.177 \\
0.266 \\
0.205\end{array}$ & $\begin{array}{c}0.23 \\
0.29 \\
0.033 \\
\end{array}$ & $\begin{array}{l}0.317 \\
0.405 \\
0.351 \\
\end{array}$ & $\begin{array}{l}0.507 \\
0.405 \\
0.086\end{array}$ & $\begin{array}{l}0.299 \\
0.207 \\
0.267\end{array}$ & $\begin{array}{l}0.202 \\
0.405 \\
0.405\end{array}$ & $\begin{array}{l}0.250 \\
0.335 \\
0.271\end{array}$ & $\begin{array}{l}0.253 \\
0.286 \\
0.139\end{array}$ & 0.205 \\
\hline $\begin{array}{ll}\text { Question review } * \\
\% & \text { written clearly } \\
\% & \text { medium/highly difficult } \\
\% & \text { Bloom's: Application, } \\
& \text { Analysis, Synthesis }\end{array}$ & & & $\begin{array}{c}85.0 \% \\
100 \% \\
85.0 \%\end{array}$ & $\begin{array}{l}95.0 \% \\
90.0 \% \\
65.0 \%\end{array}$ & $\begin{array}{l}100 \% \\
60.0 \% \\
45.0 \%\end{array}$ & $\begin{array}{l}95.0 \% \\
80.0 \% \\
75.0 \%\end{array}$ & $\begin{array}{c}100 \% \\
75.0 \% \\
45.0 \%\end{array}$ & $\begin{array}{l}95.0 \% \\
75.0 \% \\
90.0 \%\end{array}$ & \\
\hline
\end{tabular}

\section{Phase 4: Informed Changes within Departments}

Analysis of the exam results informed and motivated a closer examination of the exam itself as well as the individual core courses. In the information systems department, for example, the results prompted significant changes in the learning objectives and syllabus for the first core IS course. Reporting the point bi-serial estimated for each question motivated faculty to conduct an in-depth review of each question that was on the exam, including 
why it was included and whether it addressed any of the key learning objectives for the course. The course was completely revised based on key learning objectives and new assessment questions were submitted. Although the correlation between CCPE performance and course grades did not change greatly, there was a statistically significant improvement in the grades for the IS subtests.

The results from the economics subtests were somewhat mixed. The Microeconomics subtest scores were among the lowest, while the Macroeconomics scores were among the highest. Both subtests scores correlated well with grades, and statistically significant improvements in mean subtest scores were observed from year 1 to year 3 . The distribution of clearly written questions, medium to difficult questions, and higher cognitive questions was overall higher for both economics subtests. The in-depth review of these two courses resulted in a revision of the key learning goals and subsequent pool of assessment questions.

A closer look at the Business Statistics sequence resulted in increased discussions among those teaching the sequence as well as those upper level courses that use statistics as a pre-requisite. Business Statistics I was streamlined to increase technology and cover more applied skills and communication of results, while more projects and case studies were infused in Business Statistics II. Interestingly, key learning objectives did not change but pedagogy changes were encouraged. Additionally, the department created a statistics retention exam to be administered in a core junior-level class to measure the effect of these pedagogic changes.

\section{Phase 5: Overall Review and Evaluation of the Customized Approach}

As noted, only 55\% percent of the junior-level students had completed all nine of the freshman and sophomore core courses. The reasons for this were varied. Approximately $15 \%$ of the junior class is comprised of transfer students who came into the program with varied backgrounds. The remaining $85 \%$ includes students who failed one or more of the core courses, those who elected to avoid some of the courses they perceived as difficult, and those who participated in our study abroad program. We were faced with two options for responding to the problem. Option one was to assess only the students who had completed all nine of the core courses. This however would present a serious tracking problem and would result in assessing some students in their senior year, if they were to be assessed at all. Option two was to mark each core subtest and have the student take only the subtests corresponding to the core courses he or she had completed successfully. The second option allowed us to include all students but with a considerable amount of missing data. Furthermore, with nine possible subtests, the various permutations of subtests each student would be eligible to take was large.

There were other issues as well. Attempting to ensure that students answered questions only from the subtests corresponding to courses they had successfully completed was not entirely successful, as some students would complete subtests for courses they had not taken. Having gaps in the 'Scantron' answer form produced unreliable item analysis results from the electronic printouts. Different sample sizes of students taking different subtests required that all item analyses had to be performed by hand. Turning the raw data from the Scantron sheets into a usable dataset had to be manually organized and separated by varying numbers of students taking each subtest. Thus all point bi-serial calculations had to be done by hand after a considerable amount of organization of the data.

In addition to these somewhat operational data collection and analysis issues, we also encountered the more fundamental and impactful issue of faculty commitment. Ideally, at the end of each year of testing each department would review the results of their subtests to identify strengths and weaknesses in their respective courses. It was suggested that they select a couple of weaknesses and make adjustments in curriculum and delivery in order to strengthen these areas. This of course resulted in a significant investment of faculty time and effort, which as Bond argues is the main deterrent to the creation and deployment of common examinations (Bond, 2007). While Bond notes that the very process of 'developing and coming to consensus on assessment' through thoughtful discussion and reflection among those teaching a common core is valuable and productive, our experience was that most of our faculty simply did not feel the time invested would produce a commensurate payback. 


\section{EXPLORATION AND IMPLEMENTATION OF A STANDARDIZED APPROACH}

Two factors influenced the decision to discontinue the customized exam and initiate administration of the ETS Major Field Test (MFT) (ETS, 2012). The first factor was, frankly, the challenges involved in continuing to update and refine both the content and the delivery of the customized exam. This primarily was a faculty issue, in that 1) although expertise exists in-house, faculty are not necessarily experts in test design and validation, and 2) as is to be expected, faculty naturally tend to prioritize their time by placing more importance on personal teaching and research. In that regard, the on-going maintenance of the customized exam was exceptionally time-consumptive, and the result, as noted above, was an exam that was becoming increasingly inconsistent in quality across the various disciplines.

Therefore, we initially began to look for a solution that would be simpler to implement and thus more sustainable over a longer period of time. We reviewed various options and ultimately settled on the MFT. The MFT provided a number of advantages, ranging from the substantive (i.e., questions formulated and validated by experts) to the operational (i.e., the related benefit of not having to write, monitor and maintain the questions ourselves).

Transitioning to the MFT altered not only the assessment instrument, but also the timing, venue and nature of the target audience. The MFT is directed toward seniors near the end of their program of study, rather than toward sophomores/juniors. The MFT also could be administered within a single capstone course that all business students are required to take just prior to graduation, meaning that the appropriate venue for administration was less ambiguous. With regard to administration of the MFT in the capstone course, we followed the guidance of assessment experts, who suggest that not only should time for the exam be provided within a capstone course, but also that the students should be held accountable in some way. Katherine Martell, for example, has suggested allocating one class period and 5\% of the course grade to the MFT (Martell, 2003). This approach has worked well.

\section{COMPARING THE CUSTOMIZED AND COMMERCIAL APPROACHES}

While the decision to move from a customized to a commercial exam approach was driven primarily by operational considerations, it is important to note the relative strengths and weaknesses of the two approaches, and to highlight the contributions that each approach can make to an overall assessment program. Toward this end, we propose a framework comprised of the various criteria defining the impact of an assessment exam. They include a) relevance to learning goals, b) exam design and development, c) exam delivery, d) assessment of learning, e) impact on curriculum, and f) impact on student monitoring and management. The framework comparing the two approaches is presented in table form, as shown in Table 2.

\section{SUMMARY AND CONCLUSIONS}

In this paper we have described an evolutionary process that began with a detailed analysis of our mission and learning goals, led to the design and implementation of a customized assessment instrument tailored to the learning goals, and concluded with a reconsideration of the customized approach and the eventual implementation of the standardized Major Field Test. Given the wide array of decision criteria involved in choosing an assessment instrument, as summarized in Table 2, a key conclusion arising from this process is that the choice of an instrument targeted to program-level goals depends significantly on the individual circumstances of each institution. That is, the relative weightings of each criterion will vary. In our case, while each criterion was an important consideration, the decision to move to the MFT was influenced primarily by two of them: 1) the benchmarking capabilities of a national standardized test, and 2) by our relatively-lesser level of expertise in designing assessment instruments.

The story does not end there, however, because elements of our customized assessment instrument continue to co-exist with the standardized instrument. Lessons learned from creating customized questions tailored to learning goals in specific courses have provided input to another important aspect of program-level assessment; i.e., the use of common final exams in business core courses. The process used to generate questions for the CCPE, the knowledge of assessment attained via that process, and even some of the questions themselves (as well as many new ones) are now used in our business school across disciplines to formulate sets of common questions for many of the core courses. Like the CCPE, the common questions are targeted specifically to each course's learning goals, which 
in turn are linked to the program goals of the undergraduate program. Thus, while it no longer exists as a selfcontained assessment instrument, the CCPE and the process used to develop it continue to serve an assessment role as a complement to our other methods, including the MFT.

Table 2: Comparison of Customized and Commercial Exams by Criteria

\begin{tabular}{|c|c|c|}
\hline & $\begin{array}{l}\text { Customized Exam (CCPE) } \\
\end{array}$ & Commercial Exam (MFT) \\
\hline $\begin{array}{l}\text { Relevance to } \\
\text { learning } \\
\text { goals }\end{array}$ & $\begin{array}{l}\text { - The CCPE is a direct test of the institution's program } \\
\text { learning goals (i.e., related directly to what is being taught). } \\
\text { - Each question on the CCPE is linked to a goal (or goals) of } \\
\text { the corresponding undergraduate major (i.e., accounting, } \\
\text { finance, marketing), thus insuring relevance of each question. } \\
\text { - However - Certain questions are idiosyncratic to the teaching } \\
\text { approaches and philosophies in the business school. As such, } \\
\text { questions address what is taught, but not what should be } \\
\text { taught. }\end{array}$ & $\begin{array}{l}\text { - The MFT assesses a broader but } \\
\text { perhaps different set of learning goals. } \\
\text { - It is a benchmarking tool of what is } \\
\text { taught across institutions, and as such } \\
\text { is a potential indicator of appropriate } \\
\text { and inappropriate learning goals. } \\
\text { - However - It does not directly address } \\
\text { the institution's goals, thus perhaps } \\
\text { missing aspects of the curriculum that } \\
\text { provide a competitive advantage. }\end{array}$ \\
\hline $\begin{array}{l}\text { Exam design } \\
\text { and } \\
\text { development } \\
\text { process }\end{array}$ & $\begin{array}{l}\text { - While (or because) the exam is customizable, it also is labor- } \\
\text { intensive and not necessarily relevant to a faculty member's } \\
\text { core interests or skill set. } \\
\text { - However there are faculty gains in taking the time to engage } \\
\text { thoughtfully in the process of developing an in-house exam } \\
\text { thus driving pedagogic changes. }\end{array}$ & $\begin{array}{l}\text { - Because the exam is essentially pre- } \\
\text { fabricated, little or no additional work } \\
\text { is required to develop it. } \\
\text { - MFT questions are developed and } \\
\text { validated by assessment experts. } \\
\text { - However this can remove most } \\
\text { faculty from careful reflection of } \\
\text { current teaching practices necessary } \\
\text { for continual improvement. }\end{array}$ \\
\hline $\begin{array}{l}\text { Exam } \\
\text { delivery: } \\
\text { timing and } \\
\text { venue }\end{array}$ & $\begin{array}{l}\text { - The exam can be written to target students at any point in } \\
\text { their program of study, and covering any particular subset of } \\
\text { courses. At our institution, the CCPE targeted juniors, who } \\
\text { had completed their first two years of the business core } \\
\text { curriculum. } \\
\text { - However - Prior to the senior year, there is no single course } \\
\text { that 'makes sense' as a venue for a comprehensive } \\
\text { assessment exam. Therefore: } \\
\text { It is much harder to justify to students the relevance of } \\
\text { the exam in their course (particularly when a grade is } \\
\text { involved) } \\
\text { No sophomore- or junior-level course can assure that } \\
\text { every student will have taken all of the courses covered } \\
\text { by the exam. Thus, many students did not. }\end{array}$ & $\begin{array}{l}\text { - The exam is specifically targeted to } \\
\text { seniors, and typically is delivered } \\
\text { within the capstone course. } \\
\text { - At our institution, because every other } \\
\text { business course is a prerequisite to the } \\
\text { capstone, students taking the MFT are } \\
\text { almost assured of having taken the set } \\
\text { of courses covered in the MFT. } \\
\text { - Because the capstone course covers } \\
\text { essentially all areas of business, it is } \\
\text { much easier to justify assigning a } \\
\text { grade for the MFT. }\end{array}$ \\
\hline $\begin{array}{l}\text { Impact on } \\
\text { learning }\end{array}$ & $\begin{array}{l}\text { - Because it can be delivered prior to the senior year, the } \\
\text { customized exam can be used as a reinforcement and } \\
\text { remediation mechanism (i.e., a learning instrument as well as } \\
\text { an assessment instrument). An individual student performing } \\
\text { poorly in a particular area of the exam can be provided with } \\
\text { remedial help. }\end{array}$ & $\begin{array}{l}\text { - The MFT is an assessment instrument } \\
\text { presented at the end of a program of } \\
\text { study. As such, it is not intended as a } \\
\text { learning or remediation tool. }\end{array}$ \\
\hline $\begin{array}{l}\text { Impact on } \\
\text { courses and } \\
\text { curriculum }\end{array}$ & $\begin{array}{l}\text { - Results from the CCPE were used to identify issues in course } \\
\text { design and delivery, and to implement changes. }\end{array}$ & $\begin{array}{l}\text { - Results from the MFT were used to } \\
\text { identify issues in course design and } \\
\text { delivery, and to implement changes. }\end{array}$ \\
\hline $\begin{array}{l}\text { Impact on } \\
\text { student } \\
\text { monitoring } \\
\text { and } \\
\text { management }\end{array}$ & $\begin{array}{l}\text { - In addition to the performance results provided, the CCPE } \\
\text { also provided information that helped guide student } \\
\text { management. This included identifying and responding to } \\
\text { students who were out-of-sequence, and to students who had } \\
\text { not taken all or even most of the courses covered in the } \\
\text { CCPE. Much but not all of this was due to occasionally lax } \\
\text { enforcement of prerequisites, which has been addressed and } \\
\text { significantly improved. } \\
\text { - Although not pursued, an assessment exam prior to the senior } \\
\text { year can also be used as a hurdle, which students must pass in } \\
\text { order to proceed in their program of study. }\end{array}$ & $\begin{array}{l}\text { - Its position at the end of the program } \\
\text { of study limits the MFT as a } \\
\text { mechanism for student management. }\end{array}$ \\
\hline
\end{tabular}




\section{AUTHOR INFORMATION}

Amy L. Phelps is Assistant Professor of Statistics in the Palumbo-Donahue School of Business at Duquesne University. She teaches statistics at both the graduate and undergraduate levels, and has a particular passion for delivering exciting and meaningful pedagogy through service-learning. She also is a bio-statistician and a consultant at Magee Womens Hospital in Pittsburgh. She has published in a variety of teaching and health-related journals, including Journal of Statistics Education, Journal of Healthcare Risk Management, and Journal of Clinical Anesthesia. E-mail: phelpsa@duq.edu

William E. Spangler is Associate Dean and Professor of Information Systems Management in the PalumboDonahue School of Business. He teaches information systems and general business courses, and coordinates the School's efforts in learning outcomes assessment. His work has been published in various discipline-based and pedagogical journals, including Management Science, Journal of Management Information Systems, Communications of the ACM, and Journal of College Teaching and Learning. E-mail: spangler@duq.edu (Corresponding author)

\section{REFERENCES}

1. AACSB. (2012). Eligibility Procedures and Accreditation Standards for Business Accreditation, from http://www.aacsb.edu/accreditation/standards-busn-jan2012.pdf

2. $\quad$ Allen, M. J. (2004). Assessing Academic Programs in Higher Education. Bolton, Mass.: Anker.

3. Altbach, P. G., Gumport, P. J., \& Berdahl, R. O. (Eds.). (2011). American Higher Education in the TwentyFirst Century: Social, Political, and Economic Challenges. Baltimore, MD: Johns Hopkins University Press.

4. Angelo, T. A., \& Cross, K. P. (1993). Classroom Assessment Techniques. A Handbook for Faculty, 2nd Edition. San Francisco: Jossey-Bass.

5. Apostolou, B. A. (1999). Outcomes Assessment. Issues in Accounting Education, 14(1), 177-197.

6. Bagamery, B., Lasik, J., \& Nixon, D. (2005). Determinants of Success on the ETS Business Major Field Exam for Students in an Undergraduate Multisite Regional University Business Program. Journal of Education for Business, 81(1), 55-63.

7. Barboza, G. A., \& Pesek, J. (2012). Linking Course-Embedded Assessment Measures and Performance on the Educational Testing Service Major Field Test in Business. Journal of Education for Business, 87(2), $102-111$.

8. Barnett, S. T., Dascher, P. E., \& Nicholson, C. Y. (2004). Can School Oversight Adequately Assess Department Outcomes? A Study of Marketing Curriculum Content. Journal of Education for Business, 79(3), 157-162.

9. Bisoux, T. (2008). Measures of Success. BizEd, March/April.

10. Black, H. T., \& Duhon, D. L. (2010). Evaluating and Improving Student Achievement in Business Programs: The Effective Use of Standardized Assessment Tests. Journal of Education for Business, 79(2), 90-98.

11. Bond, L. (2007). The Case for Common Examinations. Carnegie Perspectives, http://www.carnegiefoundation.org/perspectives/case-common-examinations. Retrieved from.

12. Bush, H. F., Duncan, F. H., Sexton, E. A., \& West, C. T. (2008). Using The Major Field Test-Business As An Assessment Tool And Impetus For Program Improvement: Fifteen Years Of Experience At Virginia Military Institute. Journal of College Teaching \& Learning, 5(2), 75-88.

13. Bycio, P., \& Allen, J. S. (2007). Factors Associated With Performance on the Educational Testing Service (ETS) Major Field Achievement Test in Business (MFAT-B). Journal of Education for Business, 82(4), 196-201.

14. Callahan, T. J., Strandholm, K., \& Dziekana, J. (2009). Developing an Undergraduate Assessment Test: A Mechanism for Faculty Feedback About Retention. Journal of Education for Business, 85(1), 45-49.

15. Contreras, S., Badua, F., Chen, J. S., \& Adrian, M. (2011). Documenting and Explaining Major Field Test Results among Undergraduate Students. Journal of Education for Business, 86(2), 64-70.

16. ETS. (2012). Institutions Administering the Major Field Test in Business, September 2010 to June 2011, from www.ets.org/s/mft/pdf/2011/business4gmflistofschools.pdf 
17. Firestone, W. A., Monfils, L. F., \& Schorr, R. Y. (2004). The Ambiguity of Teaching to the Test: Standards, Assessment, and Educational Reform. Mahwah, New Jersey: Lawrence Erlbaum.

18. Kuh, G. D., \& Ewell, P. T. The state of learning outcomes assessment in the United States. Higher Education Management and Policy, 22(1), 9-28.

19. Marshall, L. L. (2007). Measuring Assurance of Learning at the Degree Program and Academic Major Levels. Journal of Education for Business, 83(2), 101-109.

20. Martell, K. (2003). Assurance of Learning: Learning Goals and Measurement. Paper presented at the MAACBA 2003 Conference, New York, NY.

21. Michlitsch, J. F., \& Sidle, M. W. (2002). Assessing Student Learning Outcomes: A Comparative Study of Techniques Used in Business School Disciplines. Journal of Education for Business, 77(3), 125-130.

22. Mirchandani, D., Lynch, R., \& Hamilton, D. (2001). Using the ETS Major Field Test in Business: Implications for Assessment. Journal of Education for Business, 77(1).

23. Peterson, M. W., \& Einarson, M. K. (2001). What Are Colleges Doing about Student Assessment? Does It Make a Difference? The Journal of Higher Education, 72(6), 629-669.

24. Pringle, C., \& Michel, M. (2007). Assessment Practices in AACSB-Accredited Business Schools. Journal of Education for Business, 82(4), 202-211.

25. Ruhland, S. K., \& Brewer, J. A. (2001). mplementing an Assessment Plan to Document Student Learning in a Two-Year Technical College. Journal of Vocational Education Research, 26(2), 141-171.

26. Terry, N., Mills, L., Rosa, D., \& Sollosy, M. (2009). Do Online Students Make The Grade On The Business Major Field ETS Exam? Academy of Educational Leadership Journal, 13(4), 109-118.

27. Terry, N., Mills, L., \& Sollosy, M. (2008). Student Grade Motivation As A Determinant Of Performance On The Business Major Field ETS Exam. Journal of College Teaching \& Learning 5(7), 27-32.

28. Thornton, B., \& Arbogast, G. (2012). Analyzing Educational Testing Service Graduate Major Field Test Results. American Journal of Business Education, 5(5), 531-538.

29. Walstad, W. B. (2001). Improving Assessment in University Economics. Journal of Economic Education, 32(3), 281-294.

30. Walvoord, B. E. (2004). Assessment Clear and Simple: A Practical Guide for Institutions, Departments, and General Education. San Francisco: Jossey-Bass.

31. Ward, C., Yates, D., \& Soong, J. Y. (2009). Exploring The Relationship Between Student Engagement And Common Business Knowledge: A Pilot Study. American Journal of Business Education, 2(9), 99-108.

32. Ward, C., Yates, D., \& Soong, J. Y. (2010). Examining The Relationship Between The National Survey Of Student Engagement And The ETS Business Major Field Test. American Journal of Business Education, 3(12), 33-40.

33. Ward, C., Yates, D., \& Soong, J. Y. (2012). Blending Research And Teamwork To Enhance Undergraduate Education: Results From National Survey Of Student Engagement And Business ETS Major Field Test. American Journal of Business Education, 5(3), 325-330.

34. Wilson, P. H. (2008). A Protocol For Analyzing The Major Field Test Results. Journal of Business and Behavioral Sciences, 19(2), 33-45. 